\title{
Determinants of high-risk fertility behavior among reproductive-age women in Ethiopia using the recent Ethiopian Demographic Health Survey: a multilevel analysis
}

\author{
Zemenu Tadesse Tessema* (i) and Koku Sisay Tamirat
}

\begin{abstract}
Background: High-risk fertility behavior is associated with numerous unfavorable child and maternal health outcomes such as chronic undernutrition, anemia, and child mortality. As far as our knowledge goes, there is not much study on determinants of high-risk fertility behavior in Ethiopia. Therefore, this study aimed to assess determinants of high-risk fertility behavior among reproductive-age women in Ethiopia.

Method: The study was based on secondary data analysis from the 2016 Ethiopia Demography and Health Survey. A total of 11,022 women who gave birth 5 years preceding the survey were included in this study. Kid's Record (KR) dataset was used. The adjusted odds ratio (AOR) with its 95\% confidence interval (Cl) was calculated for those variables included in the multilevel logistic regression model. $P$ value $\leq 0.05$ was employed to declare the statistically significant variables.

Results: More than three-fourths (76.9\%) of (95\% Cl 76.11 to 77.69 ) reproductive-age women had at least one highrisk fertility behavior. Attended primary and secondary education adjusted odds ratio (AOR) (AOR $=0.71 ; 95 \% \mathrm{Cl}$ $0.63,0.80$ and $A O R=0.73 ; 95 \% \mathrm{Cl} 0.60,0.89$, respectively), never used contraceptive ( $\mathrm{AOR}=1.25,95 \% \mathrm{Cl} 1.12,1.40$ ), unwanted pregnancies $(A O R=1.40,95 \% \mathrm{Cl} 1.23,1.59)$, had no $A N C$ visit $(A O R=1.19,95 \% C l 1.05,1.35)$, ruraldwelling $(A O R=1.26,95 \% \mathrm{Cl} 1.04,1.51$ ), regions of Ethiopia [Somalia ( $\mathrm{AOR}=1.70 ; 95 \% \mathrm{Cl} 1.24,2.32)$ and Amhara $(\mathrm{AOR}=0.72 ; 95 \% \mathrm{Cl} 0.53,0.96)]$ were determinants of high-risk fertility behavior.

Conclusion: Education, rural residence, unwanted pregnancies, no antenatal care follow-up, and never used contraceptives were determinants of high-risk fertility behavior. Therefore, increased maternal health services, special intervention for hotspot areas, and giving special attention to rural dweller women were highly recommended.
\end{abstract}

Keywords: High-risk fertility behavior, Determinants, Ethiopia, Reproductive-age women

\footnotetext{
*Correspondence: zemenut1979@gmail.com

Department of Epidemiology and Biostatistics, Institute of Public Health,

College of Medicine and Health Sciences, University of Gondar, Gondar,

Ethiopia
}

(c) The Author(s). 2020 Open Access This article is licensed under a Creative Commons Attribution 4.0 International License, which permits use, sharing, adaptation, distribution and reproduction in any medium or format, as long as you give appropriate credit to the original author(s) and the source, provide a link to the Creative Commons licence, and indicate if changes were made. The images or other third party material in this article are included in the article's Creative Commons licence, unless indicated otherwise in a credit line to the material. If material is not included in the article's Creative Commons licence and your intended use is not permitted by statutory regulation or exceeds the permitted use, you will need to obtain permission directly from the copyright holder. To view a copy of this licence, visit http://creativecommons.org/licenses/by/4.0/. 


\section{Background}

Approximately 810 women die every day, from preventable causes related to pregnancy and childbirth according to a 2017 report. Between 2000 and 2017, the maternal mortality ratio (MMR, the number of maternal deaths per 100,000 live births) dropped by about 38\% worldwide. Ninety-four percent of all maternal deaths occur in low and lower-middle-income countries. Young adolescents (ages 10-14) face a higher risk of complications and death as a result of pregnancy than other women [1]. By 2030, all countries should reduce the maternal mortality ratio (MMR) by at least two-thirds of their 2010 baseline level. The average global target is an MMR of less than 70/100,000 live births by 2030 [2]. It is currently under Sustainable Development Goal (SDG) 3 target 3.1: targeted to reduce below 70 deaths per 100, 000 live births at the end of 2030 [2]. The supplementary national target is that no country should have an MMR greater than 140/100,000 live births (a number twice the global target) by 2030 [3]. Sub-Saharan Africa had the highest MMR in 2015, an estimated 546 maternal deaths per 100,000 live births [4]. Ethiopia is one of the countries with the highest maternal mortality ratio, with 412 deaths per 100,000 live births according to the 2016 EDHS reports, of which most of the deaths were attributed to high-risk fertility behavior $[5,6]$. The global population is rapidly increasing, and according to the 2016 report, the total fertility was 2.5 and 4.8 per woman globally and in Ethiopia, respectively [7]. Fertility behavior of women is characterized by maternal age, birth spacing, and order, which has an impact on the health of women and children [8, 9]. Chronic undernutrition, anemia, and child and maternal mortality are unfavorable children and maternal health associated with highrisk fertility behavior [10-12]. Pieces of evidence from different works of the literature revealed that stillbirth, low birth weight, and prematurity were associated with high-risk fertility behavior [12-15]. The birth interval is another factor associated with high-risk fertility behavior. When birth interval got narrower, i.e., less than 24 months, the chance of child morality increased sharply compared to long-spaced birth intervals [16]. The infant born from teenage mothers increased the risk of mortality by $30 \%$ compared to their counterparts. The problem is higher in low-income countries where healthcare services are difficult to access and there are low socioeconomic conditions and high magnitude of unmet family planning need $[11,13,14,17-20]$. Also, early-age women marriage is another problem for high-risk fertility problems in Ethiopia and other low- and middleincome countries [18].

High-risk fertility behavior can be affected by sociodemographic characteristics; residence [21, 22], religion, level of education, and marital status are associated factors with high-risk fertility behavior. Similarly, reproductive health characteristics such as a history of child death, facility delivery, and family planning utilization are determinants of high-risk fertility behavior [10, 11, $13,15,18,19,23]$.

To our search and knowledge, there is a scarcity of information about determinants of high-risk fertility behavior in Ethiopia. Therefore, this study aimed to assess the determinants of high-risk fertility behavior among reproductive-age women in Ethiopia. The study will help health planners and policymakers to further reduce high-risk fertility behavior in Ethiopia and provide baseline information to other researchers.

\section{Methods}

\section{Study design, area, and period}

A population-based cross-sectional study design was used on the Ethiopian Demographic and Health Survey (EDHS) 2016 datasets. Ethiopia is situated in the Horn of Africa. It has a total area of $1,100,000 \mathrm{~km}^{2}$ and lies between latitudes $3^{\circ}$ and $14^{\circ} \mathrm{N}$, and longitudes $33^{\circ}$ and $48^{\circ}$ E. It has 9 regional states (Afar; Amhara; BenishangulGumuz; Gambela; Harari; Oromia; Somali; Southern Nations, Nationalities, and People's Region (SNNP); and Tigray) and two administrative cities (Addis Ababa and Dire Dawa). The data was collected from January 18, 2016, to June 27, 2016.

\section{Data source and study population}

The data source was EDHS 2016 IR (Individual Records) dataset. The source population was all women age 1549 years in the enumeration areas within 5 years before the survey in Ethiopia. 15,683 women aged 15-49 years were interviewed, and a weighted sample of 11,023 women was included in the study. In the 2016 EDHS, a total of 645 clusters (EAs) (202 urban and 443 rural) were selected with a probability proportional to each EAs size and independent selection in each sampling stratum. The recorded data was accessed at www.measuredhs.com on request with the help of ICF International, Inc.

\section{Data collection tools and procedures}

Ethiopian Demographic and Health Survey data were collected by two-stage stratified sampling. Each region of the country was stratified into urban and rural areas, yielding 21 sampling strata. In the first stage, 645 EAs were selected with a probability method proportional to the enumeration area size by independent selection in each sampling stratum. In the second stage of selection, a fixed number of 28 households per cluster were selected with an equal probability, systematic sampling from the newly created household listings. The detailed sampling procedure was available in the Ethiopian 
Demographic and Health Survey reports from Measure DHS website (www.dhsprogram.com) [6].

\section{Outcome variable}

For this study, we considered three parameters, maternal age at the time of delivery, birth order, and birth interval, to define the high-risk fertility behaviors. Three exposure variables were defined for this analysis. Any high-risk fertility behavior versus non-risk is coded as $1 /$ 0 , respectively. The presence of any of the following four conditions was termed high-risk fertility behavior (coded as 1 and otherwise 0 ): mothers aged less than 18 years at the time of delivery, mothers aged over 34 years at the time of delivery, the latest child born less than 24 months after the previous birth, and latest child of order three or higher. We applied the definition of "high-risk fertility behaviors" adopted by the 2016 EDHS [6].

\section{Independent variables}

Based on different literature, independent variables for this study were demographic characteristics such as sex of a child, religion, educational level, occupation, wealth index, media exposure, residence and region, and reproductive characteristics such as contraceptive use, wanted pregnancy, ANC follow-up, stillbirth, and place of delivery [10, $11,13,15,18,19,23]$.

\section{Data processing and analysis}

After data was cleaned and extracted, descriptive statistics and multilevel logistic regression analysis were done using STATA version 14.1. The data were weighted using cluster number, primary sampling unit, and strata before any statistical analysis to restore the representativeness of the survey and to tell the STATA to consider the sampling design when calculating SEs.

\section{Model building}

We fitted four models, the null model without predictors, model I with only individual-level variables, model II with only community-level variables, and model IV both individual-level and community-level variables. These models were fitted by a STATA command "xtmelogit" to identify predictors of the outcome variable. For model comparison, we used the log-likelihood ratio (LLR) and Akaike Information Criteria (AIC) tests. The highest log-likelihood and the lowest AIC win the bestfitted model.

\section{Parameter estimation methods}

In the multilevel logistic regression model, fixed effects estimates measure the association between the odds of high-risk fertility behavior (HRFB) of individual- and community-level factors with a $95 \%$ confidence interval. The random effect measures variation HRFB across clusters expressed by intraclass correlation (ICC), quantifies the degree of heterogeneity of HRFB between clusters [24]; percentage change in variance $(\mathrm{PCV})$, the proportion of the total observed individual variation in the HRFB that is attributable by cluster variations [25]; and median odds ratio (MOR), median value of the odds ratio between the cluster at HRFB and cluster at lower risk of HRFB when randomly picking out two clusters (EAs) [26].

\section{Ethics approval and consent to participate}

Ethical clearance was obtained from measure DHS through filling a form requesting for accessing data. The data used in this study are publicly available, aggregated secondary data with no personal identifying information that can be linked to study participants. The confidentiality of the data was maintained anonymously.

\section{Result}

Socio-demographic characteristics of respondents

A total of 11,022 women who gave birth in the preceding 5 years before the survey were included in the final analysis. The median age of women was 28, with an interquartile range of 25 to 34 years; about half (53\%) aged between 25 and 34 . The majority (89\%) of women were rural dwellers, most (93.1\%) were married, and about $41.4 \%$ and $34.2 \%$ were Muslim religion and Orthodox religion follower, respectively. Two-thirds (66.1\%) of the women had not attended any formal education, and $59.3 \%$ had no occupation (Table 1 ).

\section{Reproductive characteristics and high-risk fertility behaviors}

This study revealed that $76.5 \%$ (95\% CI 75.1 to 77.1 ) of women had high-risk fertility behavior, of which $31.4 \%$ were in single-risk category, $27.1 \%$ of them had a birth interval of fewer than 24 months, and about $45.1 \%$ of women were categorized in multiple high-risk groups.

Out of total mothers who participated, $43.1 \%$ of them were grand multiparous; the majority (75\%) of pregnancy for the recent births were wanted, of which threefourth $(74.4 \%)$ mothers had antenatal care follow-up for their last child. The majority (98.1\%) of women gave birth vaginally for their recent child, $72.5 \%$ delivered at home, and $8.5 \%$ had a stillbirth. About $30.1 \%$ of women had anemia during pregnancy (Table 2).

\section{Prevalence of high risk fertility behavior}

The prevalence of high-risk fertility behavior in Ethiopia was $76.90 \%$ with $95 \%$ confidence interval 76.12 to $77.69 \%$. The higher high-risk fertility $(86.18 \%)$ was detected in Somalia, and the smaller high-risk fertility behavior (64.61\%) was detected in Addis Ababa (Fig. 1) 
Table 1 Sociodemographic characteristics of women who gave birth in the preceding 5 years before the survey in Ethiopia, 2016 ( $n$ $=11,022$ )

\begin{tabular}{|c|c|c|c|c|c|}
\hline \multirow[t]{2}{*}{ Variable } & \multicolumn{2}{|c|}{ High-risk fertility problem } & \multirow[t]{2}{*}{ Total (\%) } & \multirow{2}{*}{$\begin{array}{l}\text { X- } \\
\text { square } \\
\text { value }\end{array}$} & \multirow{2}{*}{$\begin{array}{l}p \\
\text { value }\end{array}$} \\
\hline & Yes & No & & & \\
\hline \multicolumn{6}{|l|}{ Residence } \\
\hline Rural & 808 & 407 & $1215(11.03)$ & 81.55 & $<0.001$ \\
\hline Urban & 7809 & 2197 & $9807(88.97)$ & & \\
\hline \multicolumn{6}{|l|}{ Age group } \\
\hline $15-24$ & 1779 & 666 & $2445(22.19)$ & 644.08 & $<0.001$ \\
\hline $25-34$ & 4025 & 1817 & $5842(53.00)$ & & \\
\hline $35-49$ & 121 & 2613 & $2734(24.81)$ & & \\
\hline \multicolumn{6}{|l|}{ Religion } \\
\hline Orthodox & 2231 & 851 & $3082(34.22)$ & 87.82 & $<0.001$ \\
\hline Muslim & 1048 & 4394 & $5442(41.38)$ & & \\
\hline Protestant & 1385 & 477 & $1862(22.13)$ & & \\
\hline Others & 200 & 55 & $255(3.27)$ & & \\
\hline \multicolumn{6}{|l|}{ Maternal education } \\
\hline No education & 5527 & 1311 & $6837(66.08)$ & 152.37 & $<0.001$ \\
\hline Primary education & 1918 & 760 & $2678(26.77)$ & & \\
\hline Secondary & 500 & 234 & $734(4.66)$ & & \\
\hline Higher & 265 & 126 & $391(2.49)$ & & \\
\hline \multicolumn{6}{|l|}{ Marital status } \\
\hline Married & 7833 & 2423 & $10257(93.1)$ & 111 & $<0.001$ \\
\hline Single & 284 & 481 & $765(6.90)$ & & \\
\hline \multicolumn{6}{|l|}{ Husband education } \\
\hline No education & 3965 & 1090 & $5076(47.82)$ & 235 & $<0.001$ \\
\hline Primary education & 3103 & 1012 & $4115(39.34)$ & & \\
\hline Secondary & 572 & 226 & $798(7.63)$ & & \\
\hline Higher & 314 & 156 & $471(4.05)$ & & \\
\hline \multicolumn{6}{|l|}{ Maternal occupation } \\
\hline Had occupation & 3715 & 1180 & $4895(44.42)$ & 9.85 & 0.002 \\
\hline Had no occupation & 4702 & 1424 & $6126(55.58)$ & & \\
\hline \multicolumn{6}{|l|}{ Wealth index } \\
\hline Poor & 4049 & 1106 & 5155 (46.78) & 89.67 & $<0.001$ \\
\hline Middle & 1736 & 542 & $2279(20.68)$ & & \\
\hline Rich & 2630 & 955 & $3586(32.54)$ & & \\
\hline \multicolumn{6}{|l|}{ Media exposed } \\
\hline Yes & 622 & 304 & $987(8.96)$ & 88.27 & $<0.001$ \\
\hline No & 7794 & 2240 & 10035(91.04) & & \\
\hline \multicolumn{6}{|l|}{ Sex of child } \\
\hline Male & 4404 & 1320 & $5724(51.94)$ & 1.62 & 0.202 \\
\hline Female & 4013 & 1284 & $5297(48.06)$ & & \\
\hline
\end{tabular}

Individual- and community-level determinants of highrisk fertility behavior

The results of multilevel logistic regression for the individual-level and community-level variables are presented in Table 3. In the full model in which all individual-level and community-level factors included the education status of women, ANC visits during pregnancy, contraceptive utilization, wanted pregnancy, 
Table 2 Reproductive and high-risk fertility behavior of women who gave birth 5 years before the survey in Ethiopia, $2016(n=$

\begin{tabular}{|c|c|c|c|c|c|}
\hline \multirow[t]{2}{*}{ Variable } & \multicolumn{2}{|c|}{ High-risk fertility problem } & \multirow[t]{2}{*}{ Total (\%) } & \multirow{2}{*}{$\begin{array}{l}\mathrm{X}- \\
\text { square } \\
\text { value }\end{array}$} & \multirow{2}{*}{$\begin{array}{l}p \\
\text { value }\end{array}$} \\
\hline & Yes & No & & & \\
\hline \multicolumn{6}{|l|}{ Wanted pregnancy } \\
\hline Yes & 6189 & 2089 & $8279(75.11)$ & 7.89 & 0.005 \\
\hline No & 2228 & 514 & $2743(24.89)$ & & \\
\hline \multicolumn{6}{|l|}{ Place delivery } \\
\hline Home & 6234 & 1762 & $7997(72.55)$ & 68.80 & $<0.001$ \\
\hline Health institution & 2183 & 842 & $3025(27.45)$ & & \\
\hline \multicolumn{6}{|l|}{ History of stillbirth } \\
\hline Yes & 748 & 217 & $966(8.77)$ & 1.11 & 0.291 \\
\hline No & 7668 & 2387 & $10,056(91.23)$ & & \\
\hline \multicolumn{6}{|l|}{ Anemia } \\
\hline Severe & 134 & 22 & $157(1.48)$ & 31.59 & $<0.001$ \\
\hline Moderate & 694 & 150 & $744(7.00)$ & & \\
\hline Mild & 1833 & 480 & $2321(21.82)$ & & \\
\hline No anemia & 5562 & 1853 & $7416(69.70)$ & & \\
\hline \multicolumn{6}{|l|}{ Birth order } \\
\hline 1 & 2057 & 1 & $2058(18.62)$ & 1.1 & 0.412 \\
\hline $2-4$ & 2113 & 2604 & $4718(42.81)$ & & \\
\hline $5+$ & 4241 & 3 & 4245 (38.52) & & \\
\hline \multicolumn{6}{|l|}{ Parity } \\
\hline Primiparous & 1433 & 1 & $1434(13.01)$ & 1.5 & 0.123 \\
\hline Multiparous & 2266 & 2568 & $4833(43.87)$ & & \\
\hline Grand multiparity & 4716 & 35 & $4752(42.1)$ & & \\
\hline \multicolumn{6}{|l|}{ Delivery type } \\
\hline Vaginal & 8277 & 2532 & $212(1.9)$ & 6.41 & 0.011 \\
\hline Cesarean & 140 & 72 & $10,909(98.1)$ & & \\
\hline
\end{tabular}

residence, and region were elements that were significantly associated with high-risk fertility behavior.

Women who attended primary or secondary education at odds of high-risk fertility behavior decreased by 29 and 27\%, respectively, compared to those who had no formal education $(\mathrm{AOR}=0.71 ; 95 \% \mathrm{CI} 0.63$ to 0.80 and $\mathrm{AOR}=0.73 ; 95 \% \mathrm{CI} 0.60$ to 0.89 ). For those women who had not used contraceptives previously, the odds of high-risk fertility behavior were increased by $25 \%$ compared to those who had used contraceptives $(\mathrm{AOR}=1.25 ; 95 \% \mathrm{CI} 1.12$ to 1.40 ). For those women who had unwanted pregnancies, the odds of high-risk fertility behavior were $40 \%$ more likely than those who had wanted pregnancies (AOR $=1.40 ; 95 \%$ CI 1.23 to 1.59 ). For women who had not to use antenatal care visits for their recent child, the odds of high-risk fertility behavior were 19\% more likely than those who had follow-ups $(\mathrm{AOR}=1.19$; 95\% CI 1.05 to 1.35 ).
Moreover, living in a rural area was also associated with $26 \%$ increased odds of high-risk fertility behavior among women of reproductive age than urban residents $(\mathrm{AOR}=1.26 ; 95 \% \mathrm{CI} 1.04$ to 1.51$)$. Higher odds of highrisk fertility behavior were observed in the Somali regional state $(\mathrm{AOR}=1.70 ; 95 \% \mathrm{CI} 1.24$ to 2.32 ) compared with Addis Ababa. However, the odds of high-risk fertility behavior among women were lower in the Amhara region compared with Addis Ababa (AOR $=0.72$; 95\% CI 0.53 to 0.96 ) (Table 3 ).

The high-risk fertility behavior prevalence rate was not similarly distributed across the communities. About $5.4 \%$ of the variance in the odds of high-risk fertility behavior in women could be attributed to community-level factors, as calculated by the ICC based on estimated intercept component variance. The variation was also statistically significant $(p$ value $<0.001)$. After adjusting for individual-level and community-level factors, the variation in high-risk fertility behavior across 


\begin{tabular}{|c|c|c|c|c|}
\hline \multirow{3}{*}{$\begin{array}{l}\text { Region } \\
\text { Tigray }\end{array}$} & & & & \multirow{2}{*}{$\begin{array}{l}\% \\
\text { Weight }\end{array}$} \\
\hline & \multicolumn{2}{|c|}{ HRFB(Yes) Total } & Prevalence $(95 \% \mathrm{Cl})$ & \\
\hline & 536 & 716 & $74.81(71.63,77.99)$ & 6.06 \\
\hline Afar & 93 & 114 & $81.04(73.85,88.23)$ & 1.19 \\
\hline Amhara & 1459 & 2072 & $70.38(68.42,72.35)$ & 15.86 \\
\hline Oromia & 3827 & 4851 & - $78.88(77.73,80.03)$ & 46.46 \\
\hline Somali & 438 & 508 & - $86.18(83.17,89.18)$ & 6.80 \\
\hline Benishangul Gumuz & 94 & 122 & $76.89(69.40,84.38)$ & 1.09 \\
\hline SNNPR & 1742 & 2296 & $75.85(74.10,77.60)$ & 20.00 \\
\hline Gambella & 19 & 27 & $68.96(51.48,86.45)$ & 0.20 \\
\hline Harari & 19 & 26 & $+74.77(58.02,91.52)$ & 0.22 \\
\hline Addis Ababa & 158 & 244 & - $64.61(58.61,70.61)$ & 1.70 \\
\hline Dire Dawa & 36 & 47 & $77.07(65.04,89.10)$ & 0.42 \\
\hline \multicolumn{3}{|c|}{ Overall high risk fertility behavior prevalence } & $76.90(76.12,77.69)$ & 100.00 \\
\hline
\end{tabular}

communities remained statistically significant. About $1.18 \%$ of the odds of high-risk fertility behavior variation across communities were observed in the full model (model 4).

Moreover, the MOR indicated that high-risk fertility behavior was attributed to the community-level factors. The MOR for high-risk fertility behavior was 1.50 in the empty model (model 1), which showed that there were variations between communities (clustering) since MOR was 1.5 times higher than the reference $(M O R=1)$. The unexplained community variation in high-risk fertility behavior decreased to MOR of 1.20 when all factors were added to the null model (empty model). This indicates that when all elements were included, the clustering effect is still statistically significant in the full model (Table 3).

\section{Discussion}

This study revealed that more than three-fourths of women had high-risk fertility behavior of $31.4 \%$ and $45.1 \%$ in single and multiple risk categories, respectively.
The birth interval of fewer than 24 months was the most common single risk on $27.4 \%$ of women. This finding was lower than a study conducted in the Afar region of Ethiopia (86.3\%) [27]. However, this finding was higher than 58\% of 2011 EDHS report [28], 34\% in Bangladesh DHS [29], 38.3\% in Nepal [30], and 44.9\% in India [29]. The possible explanation for the observed discrepancies might be because of socio-demographic characteristic changes and increased intention of fertility in society. Specifically, compared to Asian countries such as Nepal, the socio-demographic characteristics are quite different, and the health system variations could also be the reason. In Ethiopia, child marriage is higher, which might be responsible for the increased magnitude of risky fertility behaviors [30]. Particularly, this finding was higher than the 2011 EDHS report of 58\%, which could be due to the reasons for increased fertility intention.

Those women who attended primary and secondary school associated with a decreased probability of highrisk fertility behavior compared to those with no formal education. This finding was consistent with the study 
Table 3 Multilevel logistic regression analysis of high-risk fertility behavior among reproductive-age women in Ethiopia, 2016 ( $n=$ 11,022)

\begin{tabular}{|c|c|c|c|c|c|}
\hline Variables & Category & $\begin{array}{l}\text { Model (I) AOR } \\
(95 \% \mathrm{Cl}) \text { without } \\
\text { factor }\end{array}$ & $\begin{array}{l}\text { Model (II) AOR ( } 95 \% \\
\text { Cl) individual-level } \\
\text { factor }\end{array}$ & $\begin{array}{l}\text { Model (III) AOR }(95 \% \mathrm{Cl}) \\
\text { community-level factor }\end{array}$ & $\begin{array}{l}\text { Model (IV) AOR ( } 95 \% \mathrm{Cl}) \\
\text { individual + community-level } \\
\text { factor }\end{array}$ \\
\hline \multirow[t]{2}{*}{ Sex of child } & Male & & Ref & & Ref \\
\hline & Female & & $0.94(0.85,1.03)$ & & $0.93(0.85,1.02)$ \\
\hline \multirow[t]{4}{*}{ Religion } & Orthodox & & Ref & & Ref \\
\hline & Muslim & & $1.35(1.19,1.52)$ & & $1.10(0.93,1.29)$ \\
\hline & Protestant & & $1.07(0.93,1.24)$ & & $1.08(0.89,1.30)$ \\
\hline & Others & & $1.14(0.82,1.59)$ & & $1.15(0.82,1.62)$ \\
\hline \multirow[t]{4}{*}{$\begin{array}{l}\text { Educational status of } \\
\text { mother }\end{array}$} & $\begin{array}{l}\text { Unable to } \\
\text { read and } \\
\text { write }\end{array}$ & & Ref & & Ref \\
\hline & $\begin{array}{l}\text { Primary } \\
\text { education }\end{array}$ & & $0.69(0.62,0.78)$ & & $0.71(0.63,0.80)^{*}$ \\
\hline & $\begin{array}{l}\text { Secondary } \\
\text { education }\end{array}$ & & $0.69(0.57,0.84)$ & & $0.73(0.60,0.89)^{*}$ \\
\hline & $\begin{array}{l}\text { Higher } \\
\text { education }\end{array}$ & & $0.76(0.59,0.99)$ & & $0.82(0.63,1.07)$ \\
\hline \multirow{2}{*}{$\begin{array}{l}\text { Occupational status } \\
\text { women (the mother) }\end{array}$} & Working & & Ref & & Ref \\
\hline & Not working & & $0.99(0.89,1.09)$ & & $0.96(0.87,1.06)$ \\
\hline \multirow[t]{3}{*}{ Wealth index } & Poor & & Ref & & Ref \\
\hline & Middle & & $0.90(0.78,1.04)$ & & $0.95(0.82,1.10)$ \\
\hline & Rich & & $0.91(0.80,1.04)$ & & $0.98(0.85,1.13)$ \\
\hline \multirow[t]{2}{*}{ Media exposure } & $\begin{array}{l}\text { Has media } \\
\text { exposure }\end{array}$ & & Ref & & Ref \\
\hline & $\begin{array}{l}\text { No media } \\
\text { exposure }\end{array}$ & & $0.81(0.69,0.96)$ & & $0.83(0.70,1.004)$ \\
\hline \multirow[t]{2}{*}{ Contraceptive use } & Yes & & Ref & & Ref \\
\hline & No & & $1.31(1.17,1.47)$ & & $1.25(1.12,1.40)^{*}$ \\
\hline \multirow[t]{2}{*}{ Wanted pregnancy } & Yes & & Ref & & Ref \\
\hline & No & & $1.34(1.18,1.53)$ & & $1.40(1.23,1.59)^{*}$ \\
\hline \multirow[t]{2}{*}{ Had ANC } & Yes & & Ref & & Ref \\
\hline & No & & $1.19(1.05,1.34)$ & & $1.19(1.05,1.35)^{*}$ \\
\hline \multirow[t]{2}{*}{ Stillbirth } & No & & Ref & & Ref \\
\hline & Yes & & $1.08(0.88,1.28)$ & & $1.07(0.90,1.27)$ \\
\hline \multirow[t]{2}{*}{ Delivery place } & Institution & & Ref & & Ref \\
\hline & Home & & $0.99(0.88,1.12)$ & & $0.97(0.85,1.11)$ \\
\hline \multirow[t]{2}{*}{ Residence } & Urban & & & Ref & Ref \\
\hline & Rural & & & $1.65(1.43,1.90)$ & $1.26(1.04,1.51)^{*}$ \\
\hline \multirow[t]{8}{*}{ Region } & Addis & & & Ref & Ref \\
\hline & Afar & & & $1.56(1.16,2.10)$ & $1.19(0.86,1.63)$ \\
\hline & Amhara & & & $0.81(0.61,1.08)$ & $0.72(0.53,0.96)^{*}$ \\
\hline & Oromia & & & $1.18(0.89,1.57) 2.289$ & $0.98(0.73,1.31)$ \\
\hline & Somalia & & & $2.29(1.73,3.05)$ & $1.70(1.24,2.32)^{*}$ \\
\hline & $\begin{array}{l}\text { Benishangul } \\
\text { Gumuz }\end{array}$ & & & $1.12(0.83,1.52)$ & $0.99(0.73,1.35)$ \\
\hline & SNNP & & & $1.05(0.79,1.39)$ & $0.93(0.69,1.26)$ \\
\hline & Gambela & & & $0.92(0.69,1.24)$ & $0.79(0.57,1.09)$ \\
\hline
\end{tabular}


Table 3 Multilevel logistic regression analysis of high-risk fertility behavior among reproductive-age women in Ethiopia, 2016 ( $n=$ 11,022) (Continued)

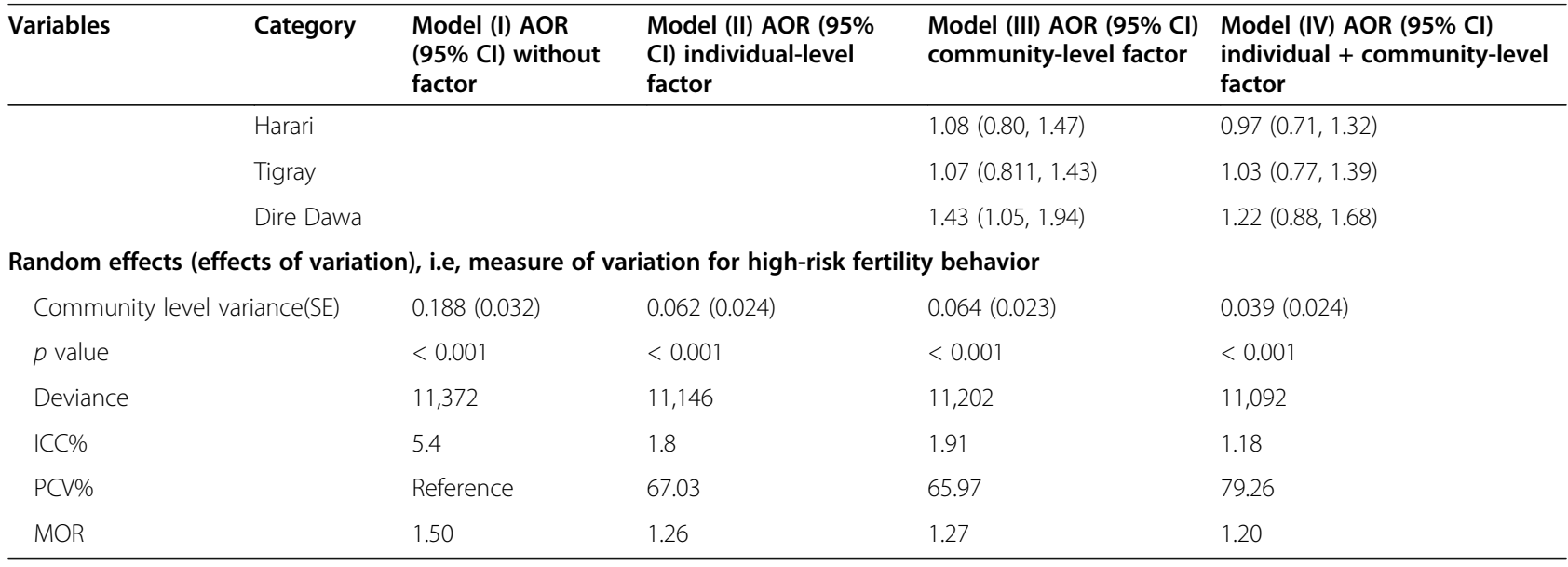

Ref reference category

${ }^{*} p$ value less than 0.05

result in Ethiopia, Nigeria, and Nepal [9, 28, 29, 31]. This could be because those attending school had better knowledge and awareness about high-risk fertility behavior and lower probability of experiencing early marriage.

Women who never used contraceptive methods previously associated with an increased occurrence of highrisk fertility behavior compared to those who had used it. This finding was supported by other studies and evidence $[18,20]$. One of the purposes of contraceptive use is spacing birth intervals and decreasing unintended pregnancies, which might affect the mother and child's health; thus, the essential postnatal services intended to widen birth intervals through the provision of family planning services [23].

Women who had a history of unwanted pregnancies were more likely to had high-risk fertility behavior than wanted pregnancies. The possible reason might be women who had experienced unwanted pregnancies is an indicator of low family planning utilization. This finding was consistent with other studies conducted in Nigeria [9].

Women who were rural dwellers have increased odds of high-risk fertility behavior compared to those urban dwellers. This finding was consistent with the study conducted in Ethiopia [28]. The possible reason might be women in rural areas are highly disadvantaged in terms of reproductive health services besides low literacy levels in rural areas. Those women who had no ANC follow-ups to the recent children were associated with increased risky fertility behaviors. During ANC, follow-up clinical checkups were made for the mother and fetus. Furthermore, counseling about postnatal care included family planning choices for the widening of intervals between births. Thus, the low utilization of ANC during pregnancy might contribute to high-risk fertility behavior.
Compared to Addis Ababa women who reside in the Somalia region, the high-risk fertility behaviors were doubled. In contrast, for women who live in the Amhara region, high-risk fertility behavior were decreased. This might be explained by health service inaccessibility and low family planning acceptance rates due to community beliefs and myths from religious perspectives. Moreover, in the Somali region, the community follows nomadic ways of life and has difficulty with health services in addition to a serious security problem.

This study has strengths of the data being nationally representative, the multilevel analysis used to account cluster correlations. However, this study has faced the following limitations: firstly, the study's cross-sectional nature affects the cause-effect relationship. Secondly, health system characteristics were not assessed; lastly, the data of this study had problems of recall bias, such as several months for the birth interval.

\section{Conclusion}

In this study, high-risk fertility behavior was high with significant regional variations. Education, rural residence, unwanted pregnancies, no antenatal care followup, and never used contraceptives were determinants of high-risk fertility behavior. Therefore, increased maternal health services, special intervention for hotspot areas, and giving special attention to rural dweller women were highly recommended.

\section{Abbreviations}

ANC: Antenatal care; AOR: Adjusted odds ratio; Cl: Confidence interval; DHS: Demographic and health survey; EA: Enumeration area; E: East; EDHS: Ethiopian Demographic and Health Survey; ICC: Intraclass correlation; KR: Kid's Record; LLR: Likelihood ratio; MOR: Median odds ratio; N: North: PCV: Proportion of cluster variance; SE: Standard error; SGD: Sustainable development goal; SNNP: Southern Nations, Nationalities, and People's Region 


\section{Acknowledgements}

We would like to thank the Ethiopian Central Statistics Agency for providing us with all the relevant secondary data used in this study. Finally, we would like to thank all who directly or indirectly supported us.

\section{Authors' contributions}

ZTT and KST conceived the study, are involved in the study design and data analysis, drafted the manuscript, and critically reviewed the manuscript. All authors read and approved the final manuscript.

\section{Funding}

We did not receive external funds for this research.

\section{Availability of data and materials}

The datasets used during the current study are available from the corresponding author

\section{Ethics approval and consent to participate}

Ethical approval was obtained from measure DHS through filling a form requesting for accessing data. The data used in this study are publicly available, aggregated secondary data with no personal identifying information that can be linked to study participants. The confidentiality of data was maintained anonymously.

\section{Consent for publication}

Not applicable as there is no image or other confidentiality related issues.

\section{Competing interests}

The authors declared that they have no competing interests.

Received: 8 June 2020 Accepted: 29 October 2020

Published online: 27 November 2020

\section{References}

1. World Health Organization (WHO). Maternal mortality 2019. Available from: https://www.who.int/news-room/fact-sheets/detail/maternal-mortality.

2. Kumar S, Kumar N, Vivekadhish S. Millennium development goals (MDGS) to sustainable development goals (SDGS): addressing unfinished agenda and strengthening sustainable development and partnership. Indian J community Med Off Publ Indian Assoc Prev Soc Med. 2016;41(1):1.

3. Document U, Comment USE, To F, Epmm T. Strategies toward ending preventable maternal mortality ( EPMM ). 2015;6736(2013):1-4.

4. Filippi V, Chou D, Ronsmans C, Graham W, Say L. Levels and causes of maternal mortality and morbidity. Dis Control Priorities, Third Ed (Volume 2) Reprod Matern Newborn, Child Heal. 2016;51-70.

5. Goovaerts P. Geostatistical approaches for incorporating elevation into the spatial interpolation of rainfall. J Hydrol. 2000;228(1-2):113-29.

6. Central Statistical Agency. Ethiopia demographic and health survey 2016. Calverton: ORC Macro; 2016

7. Tadesse G. Women empowerment and their reproductive behaviour among currently married women in Ethiopia: Addis Ababa University; 2018. http://localhost:80/xmlui/handle/123456789/15137.

8. Asghar M, Murry B, Saraswathy KN. Fertility behaviour and effect of son preference among the Muslims of Manipur, India. J Anthropol. 2014;2014.

9. Adiri F, Ibrahim HI, Ajayi V, Sulayman HU, Yafeh AM, Ejembi CL. Fertility behaviour of men and women in three communities in Kaduna state, Nigeria. Afr J Reprod Health. 2010;14(3):97-105.

10. Casterline JB. Determinants and consequences of high fertility: a synopsis of the evidence-portfolio review. The World Bank; 2010.

11. Adhikari R. Demographic, socio-economic, and cultural factors affecting fertility differentials in Nepal. BMC Pregnancy Childbirth. 2010;10(1):19.

12. Balasch J, Gratacós E. Delayed childbearing: effects on fertility and the outcome of pregnancy. Curr Opin Obstet Gynecol. 2012;24(3):187-93.

13. Fall CHD, Sachdev HS, Osmond C, Restrepo-Mendez MC, Victora C, Martorell $\mathrm{R}$, et al. Association between maternal age at childbirth and child and adult outcomes in the offspring: a prospective study in five low-income and middle-income countries (COHORTS collaboration). Lancet Glob Heal. 2015; 3(7):e366-77.

14. Jonas K, Crutzen R, van den Borne B, Sewpaul R, Reddy P. Teenage pregnancy rates and associations with other health risk behaviours: a three- wave cross-sectional study among South African school-going adolescents. Reprod Health. 2016;13(1):50.

15. Rutstein SO, Winter R. Contraception needed to avoid high-fertility-risk births, and maternal and child deaths that would be averted. Farifax: ICF International; 2015.

16. Isabirye A. The effects of high risk fertility behavior on child survival in Uganda. (Doctoral dissertation, Makerere University); 2012.

17. Kulldorff M. SaTScan user guide. Boston: StatScan; 2006.

18. Brown W, Ahmed S, Roche N, Sonneveldt E, Darmstadt GL. Impact of family planning 348 programs in reducing high-risk births due to younger and older maternal age, short birth 349 intervals, and high parity. In: Seminars in perinatology. Elsevier; 2015. p. 338-44.

19. Hasan A, Singh MK, Khan AA. Fertility behaviour and contraceptive use in urban slums of district Gorakhpur. Int J Community Med Public Heal. 2017; 4(12):4702-5.

20. Rutstein SO, Winter R. The effects of fertility behavior on child survival and child nutritional status: evidence from the Demographic and Health Surveys 2006 to 2012; 2014

21. Ndiaye K, Portillo E, Ouedraogo D, Mobley A, Babalola S. High-risk advanced maternal age and high parity pregnancy: tackling a neglected need through formative research and action. Glob Heal Sci Pract. 2018;6(2):37080 .

22. Rahman M, Islam MJ, Haque SE, Saw YM, Haque MN, Duc NHC, et al. Association between high-risk fertility behaviours and the likelihood of chronic undernutrition and anaemia among married Bangladeshi women of reproductive age. Public Health Nutr. 2017;20(2):305-14.

23. Singer Babiarz K, Miller G, Valente C, Lee J, Tey NP. Family planning and fertility behavior: evidence from twentieth century Malaysia. Cent Glob Dev Work Pap. 2017:470

24. Merlo J, Chaix B, Ohlsson H, Beckman A, Johnell K, Hjerpe P, et al. A brief conceptual tutorial of multilevel analysis in social epidemiology: using measures of clustering in multilevel logistic regression to investigate contextual phenomena. J Epidemiol Community Health. 2006;60(4):290-7.

25. Guo G, Zhao H. Multilevel modeling for binary data. Annu Rev Sociol. 2002; 26(1):441-62.

26. Larsen K, Merlo J. Appropriate assessment of neighborhood effects on individual health: integrating random and fixed effects in multilevel logistic regression. Am J Epidemiol. 2005;161(1):81-8.

27. Alemu T. Assessment of Relationship between Infant Death and High Risk Fertility Behavior among Married Women of Afar. Zone Four (Doctoral dissertation, Addis Ababa University); 2006.

28. Dejene EG and T. Correlates of high risk fertility behaviour in Ethiopia: a multilevel analysis of the 2011 Ethiopian Demographic and Health Survey Data. J Heal Med Nurs. 2017;39(ISSN 2422-8419).

29. Rahman M, Haque SE, Zahan S, Islam J, Rahman M, Asaduzzaman MD, et al. Maternal high-risk fertility behavior and association with chronic undernutrition among children under age $5 \mathrm{y}$ in India, Bangladesh, and Nepal: do poor children have a higher risk? Nutrition. 2018;49:32-40.

30. Marshall EP, Lyytikainen M, Jones N, Montes A, Pereznieto P, Tefera B. Child marriage in Ethiopia: a review of the evidence and an analysis of the prevalence of child marriage in hotspot districts. UNICEF Ethiopia and Overseas Development Institute (ODI). 2016. https://www.odi.org/ publications/10452-child-marriage-ethiopia-review-evidence-and-analysisprevalence-child-marriage-hotspot-districts.

31. Kulu H, Boyle PJ. High fertility in city suburbs: compositional or contextual effects? Eur J Popul Eur Démographie. 2009;25(2):157-74.

\section{Publisher's Note}

Springer Nature remains neutral with regard to jurisdictional claims in published maps and institutional affiliations. 